\title{
Determinants of prelacteal feeding practice among postpartum mothers in Debre Markos town, Amhara regional state, Ethiopia, 2016
}

This article was published in the following Dove Press journal:

Nutrition and Dietary Supplements

Tenaw Gualu

Abebe Dilie

Dessalegn Haile

Abebe Abate

Department of Nursing, College of Health Sciences, Debre Markos University, Debre Markos, Ethiopia
Correspondence: Tenaw Gualu Department of Nursing, College of Health Science, Debre Markos University, PO Box 269, Debre Markos, Ethiopia Email tenaadam21@gmail.com
Background: Prelacteal feeding (PLF) is giving liquids or food other than breast milk prior to the establishment of regular breast-feeding (colostrum). The practice of PLF is common in Ethiopia. PLF deprives the child of the valuable nutrients and the protection of colostrum and exposes the newborn to the risk of infection. There are limited studies conducted so far on this topic, and even then, findings are inconsistent.

Objective: The objective of this study was to assess determinants of PLF practice and associated factors among postpartum mothers in Debre Markos town, Amhara Regional State, Ethiopia, 2016.

Methods: A community-based cross-sectional study was conducted among 262 mothers (postpartum) with infants. Census data was used to include all the postpartum mothers and infant pairs. Structured interviewer-administered questionnaires were used to collect data. The data were cleaned, coded, and entered in Epi data version 3.1 and transferred to SPSS version 20.0 for analysis. Frequency and percentage were used to summarize the sociodemographic characteristics. Variables with a $P$-value of $<0.05$ in multivariate analysis were declared statistically significant at a $95 \%$ confidence interval.

Result: Approximately 50 (19.1\%) of the mothers had given one prelacteal feed before initiating colostrum. Cow milk, butter, clean water, sugar, honey, salt, and tea were the most common prelacteal feeds used. Inability to read and write 3.5 (1.14-10.75), giving birth to a male 2.8 (1.23-6.37), home delivery 4.4 (1.78-10.85), breast-feeding initiation after 24 hours 6.4 (2.38-17.18), and previous experience with PLF 3.7 (1.48-9.22) were factors positively associated with PLF.

Conclusion and recommendation: It was observed that the prevalence of PLF was relatively high in the study area (19.1\%). Education status of the mother, infant's sex, timing of breastfeeding initiation, site of delivery, and previous experience with PLF were factors associated with PLF. Education should be provided to promote institutional delivery and increase awareness about the importance of exclusive breast-feeding.

Keywords: prelacteal feeding, practice, factors, Debre Markos, Ethiopia

\section{Introduction}

Human breast milk is primarily colostrum immediately following birth. Colostrum gradually changes to mature milk over the next several days. ${ }^{1}$ Early breast-feeding practices determine the successful establishment and duration of breast-feeding. It is recommended that children be put to the breast immediately or within one hour after birth. When a mother initiates breast-feeding immediately after birth, breast milk production is stimulated. ${ }^{2}$

It is recommended to make breast milk a baby's first taste, and no prelacteal feeds such as fenugreek water, water with sugar, thin gruel, other liquids, or ritual foods submit your manuscript $\mid$ www.dovepress.com 
should be given to the infant. ${ }^{3}$ Prelacteal feeding (PLF) is giving liquids or foods other than breast milk prior to the establishment of regular breast-feeding. ${ }^{2}$

PLF deprives the child of the valuable nutrients and protection of colostrum, and exposes the newborn to the risk of infection. ${ }^{2}$ Globally, only (38\%) of infants are exclusively breastfed. Suboptimal breast-feeding contributes to 800,000 infant deaths globally. Exclusive breast-feeding, the practice of only giving an infant breast milk for the first 6 months of life (no other food or water), provides protection against respiratory infections, diarrheal disease, other life-threatening ailments, and obesity and noncommunicable diseases such as asthma and diabetes. ${ }^{4}$

However, in many contexts, PLF is also popular in Ethiopia. The practice of PLF remains high in Ethiopia. For example, it was found that approximately $38.8 \%$ of women in Raya Kobo district and $45.4 \%$ of mothers in Harar gave prelacteal liquids to their infants. ${ }^{5,6}$

The most common prelacteal foodstuffs are milk other than breast milk, plain water, sugar or glucose water, fresh butter, Ersho, salt water solution, fruit juice, infant formula, tea, and honey. ${ }^{5,6}$ The most common reasons stated for PLF are insufficient milk production, advice from elders, family custom, assumption that it is good for health (child will talk early and tongue will become thin), to remove meconium from the gut of the child, and to prevent "evil eye" and illness. ${ }^{5,7}$

The main risk factors associated with PLF practice include home delivery, lack of awareness of the risks associated with PLF, late initiation of breast-feeding, and influence by friends and relatives to give prelacteal feeds for their newborn. ${ }^{5,6}$

There are limited studies conducted on this topic in Ethiopia. Even the studies conducted on this and related topics show inconsistencies among their findings. ${ }^{5,6,8,9}$ As a result, PLF is emerging as an additional factor to be targeted through educational research.

Conducting a study about PLF in this area will have paramount importance and help to identify the current gaps and supplement the past studies. Thus, the study can be used as a reference for health care providers, health care educators, policymakers, and future researchers in this and/ or related fields.

\section{Objective}

The aim of this study was to assess determinants of PLF practice and associated factors among postpartum mothers (mothers who gave live birth, have infants currently and within 6 months of period after giving birth) in Debre Markos town, Amhara Regional State, Ethiopia, 2016.

\section{Methods}

\section{Study area}

The study was conducted in Debre Markos town. Debre Markos is found in East Gojjam Zone of Amhara regional state of Ethiopia. It is $300 \mathrm{~km}$ away from Addis Ababa, the capital of Ethiopia and $265 \mathrm{~km}$ away from Bahir Dar, capital of Amhara regional state. Its geographical location is $10^{\circ} 20^{\prime} \mathrm{N}, 37^{\circ} 43^{\prime} \mathrm{E}$. It has an elevation of 2446 meters. The town has one referral hospital and four health centers.

\section{Study period}

The study was conducted from September to October 2016.

\section{Study design}

A community-based cross-sectional study design was used.

\section{Source population}

The source population included all postpartum mother and infant pairs in Debre Markos town.

\section{Study population}

All postpartum mother and infant pairs in Debre Markos town who fulfilled the inclusion criteria were included in the study.

\section{Inclusion criteria}

The inclusion criteria were as follows: all postpartum mothers (aged 18 and above) and infants who had lived for at least for 6 months in the study area.

\section{Exclusion criteria}

Those who were unwilling to participate and seriously ill or unable to give the required information during data collection period were not included in the study.

\section{Sample size}

Because the number of postpartum mothers was less in the town, all the postpartum mothers were included. Therefore, the total sample size was all the 262 postpartum mother and infant pairs found in the town.

\section{Sampling procedure}

There are seven kebeles in Debre Markos town. The number of postpartum mothers was taken from the family folder of the respective kebele's community health workers. All the postpartum mothers and their infants were included in the study. To reach to every single postpartum mother and infant pair, the houses they live in were labeled with the help of the respective kebele's community health worker. During the data 
collection time, if a multiple births scenario was encountered, one infant was selected by lottery method for the study.

\section{Instruments and personnel}

Structured close- and open-ended questionnaires were adapted from previous research done on similar topics. ${ }^{5,6}$ The questionnaire was first prepared in English. Later, it was translated in to the local language Amharic and then back again to English. Five graduating midwifery students participated as data collectors. Two supervisors monitored the overall data collection process.

\section{Data quality control}

Orientation and training was given to data collectors regarding purpose of study and ethical issues. Pretesting was done on $5 \%$ of the actual study subjects in the study area. After pretesting, vague terms and questions were discarded.

\section{Data processing and analysis}

The data were cleaned, coded, and entered in Epi data version 3.1 and transferred to SPSS version 20.0 (IBM Corp., Armonk, NY, USA) for analysis. Both descriptive and inferential statistics were used to analyze and present the data. Frequency and percentage were used to summarize descriptive values. Inferential statistics like odds ratio, binary logistic regression, and multivariate logistic regression were used to determine if there was association between dependent and independent variables. After bivariate analysis, only those variables with $P$-value $<0.05$ were entered for further multivariate analysis. A $P$-value of $<0.05$ in multivariate analysis was considered statistically significant at $95 \%$ confidence interval.

\section{Ethical issues}

Ethical clearance for this study was obtained from the research and publication committee of Debre Markos University, College of Health Sciences. The approval of the research and publication committee was found sufficient for this study. The purpose and importance of the study was explained to mothers. Informed written consent was obtained from the participants. For those who were unable to read and write, informed written consent was taken after reading the consent in front of the participant with one family member who can read and write. Privacy and confidentiality was maintained throughout the study.

\section{Results}

The study included all the 262 postpartum mothers found in the town. This made the response rate of the study $100 \%$. The majority of the participants, 144 (55\%), were aged between
29 and 39 years. Approximately 241 (92\%) participants were Orthodox Christians, while 258 (98.5\%) were Amhara in ethnicity (Table 1).

Among the mother-infant pairs, 154 (58.8\%) of the infants were males. Approximately 167 (63.8\%) infants had normal birth weight (2,500-4,000 g). Approximately 205 (78.2\%) infants were fed breast milk within an hour of birth (Table 2).

Among pregnancy and related factors, approximately $222(84.7 \%)$ mothers gave birth at gestational age of $37-42$ weeks. Approximately 232 (88.5\%) of the mothers had antenatal care follow-up. Similarly, 219 (83.6\%) mothers gave birth at health institutions (Table 3 ).

From the total respondents, $166(63.4 \%)$ have ever heard about PLF and approximately 50 (19.1\%) mothers had given one prelacteal feed before initiating colostrum.

Respondents were asked to list what their reasons were for using prelacteal foods. Among the participants who used

Table I Sociodemographic characteristics of the mothers in Debre Markos town, Amhara regional state, North West Ethiopia, September 2016, included in the study ( $N=262)$

\begin{tabular}{|c|c|c|}
\hline Variables & & Frequency \\
\hline \multirow[t]{3}{*}{ Age, years } & $18-28$ & $103(39.3 \%)$ \\
\hline & $29-39$ & 144 (55\%) \\
\hline & $>40$ & $15(5.7 \%)$ \\
\hline \multirow[t]{6}{*}{ Educational level } & Cannot read and write & $36(13.7 \%)$ \\
\hline & Read and write & $38(14.5 \%)$ \\
\hline & $\begin{array}{l}\text { Primary education (grades } \\
\mid-8 \text { ) }\end{array}$ & $40(15.3 \%)$ \\
\hline & Secondary education (grades & $67(25.5 \%)$ \\
\hline & $9-12)$ & \\
\hline & College and above & 81 (31\%) \\
\hline \multirow[t]{3}{*}{ Religious affiliation } & Orthodox Christian & $24 I(92 \%)$ \\
\hline & Muslim & $16(6.1 \%)$ \\
\hline & Catholic Christian & $5(1.9 \%)$ \\
\hline \multirow[t]{3}{*}{ Ethnicity } & Amhara & 258 (98.5\%) \\
\hline & Oromo & $3(1.1 \%)$ \\
\hline & Tigre & $\mathrm{I}(0.4 \%)$ \\
\hline \multirow[t]{4}{*}{ Marital status } & Not married & $31(11.8 \%)$ \\
\hline & Married & $223(85.1 \%)$ \\
\hline & Divorced & $7(2.7 \%)$ \\
\hline & Widowed & $\mathrm{I}(0.4 \%)$ \\
\hline Average monthly & $\leq 1,000$ & 47 (I7.9\%) \\
\hline \multirow[t]{2}{*}{ family income (ETB) } & $\mathrm{I}, 00 \mathrm{I}-2,500$ & $40(15.3 \%)$ \\
\hline & $>2,500$ & 175 (66.8\%) \\
\hline \multirow[t]{2}{*}{ Employment status } & Employed & $176(67.2 \%)$ \\
\hline & Unemployed & $86(32.8 \%)$ \\
\hline \multirow[t]{3}{*}{ Type of family } & Nuclear & 240 (9l.6\%) \\
\hline & Single parent & $9(3.4 \%)$ \\
\hline & Extended & $13(5 \%)$ \\
\hline \multirow[t]{3}{*}{ Family size } & $2-3$ & $77(29.4 \%)$ \\
\hline & $4-5$ & $163(62.2 \%)$ \\
\hline & $>6$ & $22(8.4 \%)$ \\
\hline
\end{tabular}

Abbreviation: ETB, Ethiopian birr. 
Table 2 Characteristics of the newborn infants in Debre Markos town, Amhara regional state, North West Ethiopia, September 2016, included in the study $(\mathrm{N}=262)$

\begin{tabular}{lll}
\hline Variables & & Frequency \\
\hline Sex & Male & $154(58.8 \%)$ \\
Birth weight in grams & Female & $108(41.2 \%)$ \\
& $<I, 000$ & $3(1.1 \%)$ \\
& $I, 000-I, 500$ & $11(4.2 \%)$ \\
& $I, 500-2,500$ & $69(26.3 \%)$ \\
& $2,500-4,000$ & $167(63.8 \%)$ \\
Birth order & $>4,000$ & $12(4.6 \%)$ \\
& $I$ & $116(44.3 \%)$ \\
& 2 & $76(29 \%)$ \\
History of admission to & 3 & $47(17.9 \%)$ \\
neonatal intensive care unit & Yes & $18(6.9 \%)$ \\
Timing of breast-feeding & Within I hour & $5(1.9 \%)$ \\
initiation & I-24 hours & $37(14.1 \%)$ \\
& After I day & $225(85.9 \%)$ \\
& & $28(10.7 \%)$ \\
\hline
\end{tabular}

Table 3 Pregnancy and related factors among postnatal mothers in Debre Markos town, Amhara regional state, North West Ethiopia, September 2016 ( $N=262)$

\begin{tabular}{lll}
\hline Variables & & Frequency \\
\hline Gestational age at & $<32$ & $2(0.8 \%)$ \\
birth (in weeks) & $32-37$ & $34(13 \%)$ \\
& $37-42$ & $222(84.7)$ \\
Gravida & $\geq 42$ & $4(1.5 \%)$ \\
& 1 & $120(45.8 \%)$ \\
& 2 & $71(27.1 \%)$ \\
& 3 & $48(18.3 \%)$ \\
Parity & 4 & $18(6.9 \%)$ \\
& 5 & $5(1.9 \%)$ \\
& 1 & $123(46.9 \%)$ \\
Antenatal care & 2 & $79(30.2 \%)$ \\
follow-up & 3 & $45(17.2 \%)$ \\
Site of antenatal care & Private institution & $10(3.8 \%)$ \\
follow-up & Governmental institution & $215(82.1 \%)$ \\
Mode of delivery & Spontaneous vaginal & $241(92 \%)$ \\
& Cesarean section & $21(8 \%)$ \\
Site of delivery & Home & $43(16.4 \%)$ \\
Breast-feeding & Health institution & $219(83.6 \%)$ \\
counseling from staff & Yes & $207(79 \%)$ \\
\hline & No & $55(21 \%)$ \\
\hline
\end{tabular}

prelacteal foods, $30(60 \%), 26(52 \%), 24(48 \%), 23(46 \%), 13$ (26\%), and $12(24 \%)$ mentioned insufficient milk production, advice from elders, family custom, that it was good for health, prevention of evil eye and illness, and removal of meconium as the main reasons for use prelacteal feeds, respectively.

Respondents were asked what prelacteal food they had used for their current infant. Among the total 50 mothers who used prelacteal feeds, 39 (78\%) had used cow milk (Figure 1).

In bivariate analysis, educational level of the mother, sex of the infant, timing of breast-feeding initiation, antenatal care follow-up, place of delivery, breast-feeding counseling from health care providers, and previous experience with PLF were significantly associated with PLF practice. In multivariate analysis, educational status of the mother, sex of the infant, timing of breast-feeding initiation, site of delivery, and previous experience with PLF were found to be associated with PLF (Table 4).

\section{Discussion}

In this study, approximately $50(19.1 \%)$ of the postnatal mothers had given one of the prelacteal feeds before initiating colostrum. This number is lower than that in a study done previously in different parts of the world. ${ }^{7,-13}$ It is also lower than the results found in different parts of Ethiopia. $5,6,14$

However, it is slightly higher than the result of a study done in Nigeria. ${ }^{15}$ The difference might stem from the sociodemographic differences among the study participants and methodological differences among the studies.

Adjusting for other factors, educational status of the mothers was associated with PLF. Mothers who are unable to read and write were 3.5 times more likely to give prelacteal feed to their newborns when compared to mothers who were educated to a college level or above. The result is in line with a previous study done in a rural area of Maharashtra. ${ }^{7}$ This may be because mothers with low education level are not aware of the risks associated with prelacteal feeds.

Male birth was associated with PLF. Mothers who gave birth to male infants were 2.8 times more likely to give prelacteal feed to their newborns when compared to mothers who gave birth to female infants. This finding was supported by a previous study. ${ }^{13}$ However, it is not in line with a study done in Egypt where there is a preponderance for PLF in female babies. ${ }^{11}$ This might be from the difference in cultures between the study populations; in Ethiopia, male birth is given due emphasis, and PLF sometimes is given, believing that it helps the baby's growth.

The odds of PLF among mothers with history of home delivery were higher when compared to those with a history of institutional delivery. The result is in line with studies done previously. ${ }^{6,7}$

Similarly, the odds of PLF among mothers with late initiation of breast-feeding were higher. Mothers who initiated 


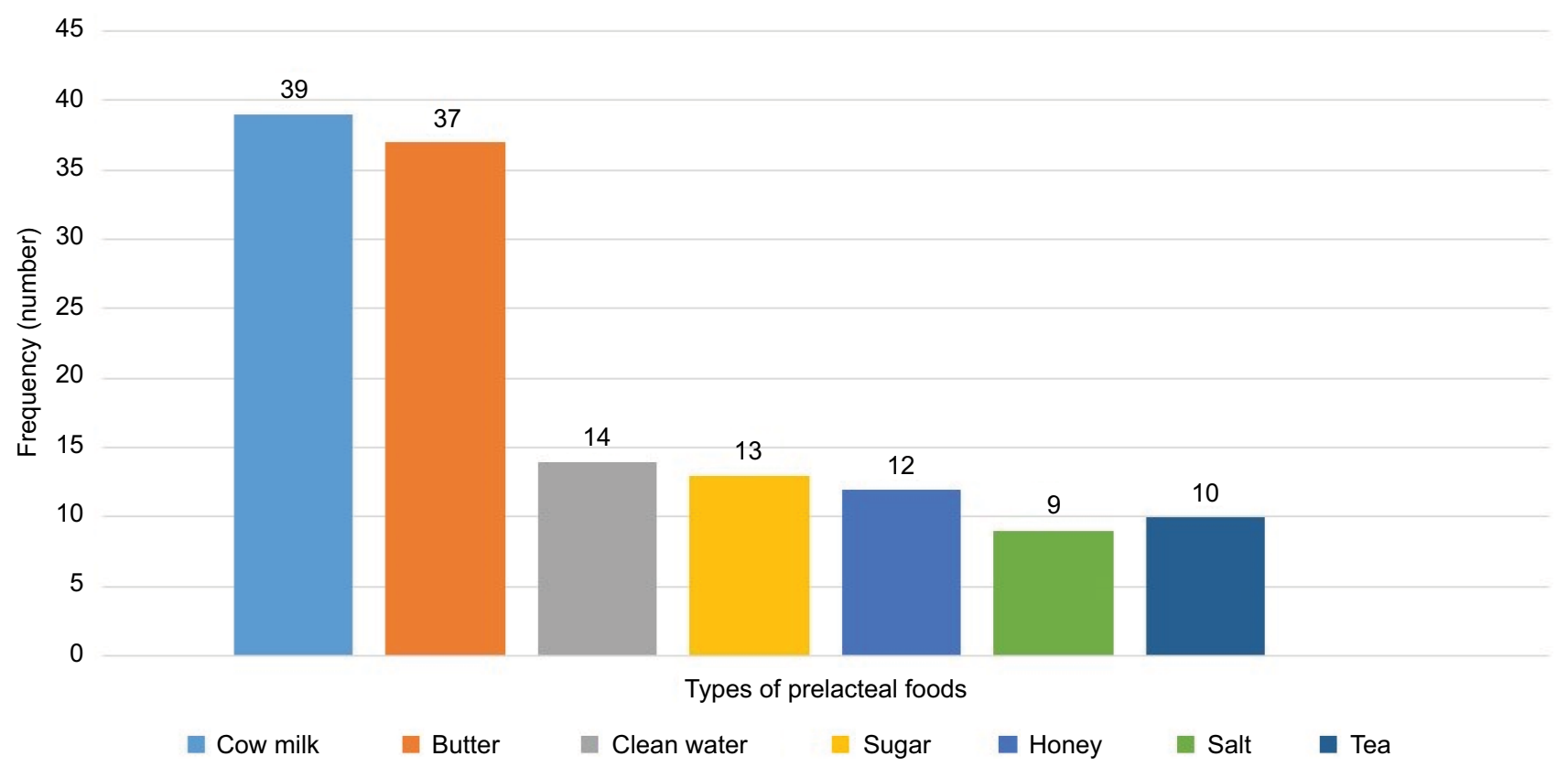

Figure I Types of prelacteal foods used by postnatal mothers in Debre Markos town, Amhara region, North West Ethiopia, September, 2016.

Table 4 Factors associated with PLF practice among postnatal mothers in Debre Markos town, Amhara regional state, North West Ethiopia, September $2016(\mathrm{~N}=262)$

\begin{tabular}{|c|c|c|c|c|c|c|}
\hline \multirow[t]{2}{*}{ Variables } & & \multicolumn{4}{|l|}{ PLF } & \multirow[t]{2}{*}{$P$-value } \\
\hline & & Yes & No & COR $(95 \% \mathrm{Cl})$ & AOR (95\%Cl) & \\
\hline \multirow[t]{5}{*}{ Educational status } & Cannot read and write & 14 & 22 & 4.5 (I.76-II.II.59) & $3.5(1.14-10.75)^{*}$ & 0.029 \\
\hline & Read and write & 11 & 27 & $2.9(1.10-7.59)$ & & \\
\hline & Primary (grades I-8) & 6 & 34 & $1.25(0.42-3.73)$ & & \\
\hline & Secondary (grades 9-12) & 9 & 58 & I.I (0.42-2.89) & & \\
\hline & College and above & 10 & 71 & I & I & \\
\hline \multirow[t]{2}{*}{ Infant's sex } & Male & 39 & 115 & $2.99(1.45-6.15)$ & $2.8(1.23-6.37)^{*}$ & 0.015 \\
\hline & Female & 11 & 97 & 1 & 1 & \\
\hline \multirow[t]{2}{*}{ Antenatal care follow-up } & Yes & 38 & 194 & I & & \\
\hline & No & 12 & 18 & $3.4(1.52-7.64)$ & & \\
\hline \multirow[t]{2}{*}{ Place of delivery } & Home & 20 & 23 & $5.48(2.69-11.17)$ & $4.4(1.78-10.85)^{*}$ & 0.001 \\
\hline & Health institution & 30 & 189 & 1 & 1 & \\
\hline Timing of breast-feeding & Within I hour & 27 & 178 & 1 & I & \\
\hline \multirow[t]{2}{*}{ initiation } & $\mathrm{I}-24$ hours & 7 & 21 & $2.2(0.85-5.66)$ & & \\
\hline & After 24 hours & 16 & 13 & $8.1(3.52-18.73)$ & $6.4(2.38-17.18)^{*}$ & 0.000 \\
\hline Breast-feeding counseling & Yes & 32 & 175 & 1 & & \\
\hline from health care & No & 18 & 37 & $2.66(1.35-5.24)$ & & \\
\hline \multicolumn{7}{|l|}{ providers } \\
\hline Previous experience with & Yes & 41 & 125 & $3.17(1.47-6.86)$ & $3.7(\mathrm{I} .48-9.22)^{*}$ & 0.05 \\
\hline PLF & No & 9 & 87 & 1 & 1 & \\
\hline
\end{tabular}

Notes: I= Reference $*$ P-value $<0.05$ (significant).

Abbreviations: AOR, adjusted odds ratio; COR, crude odds ratio; PLF, prelacteal feeding.

breast-feeding after 24-hours were 6.4 times more likely to give prelacteal feeds when compared to mothers who initiated breast-feeding within an hour of birth. The result is in congruence with studies done previously. ${ }^{5,6}$

Mothers who had previous experience with PLF were 3.7 times more likely to give prelacteal feeds to their newborns than those who did not have previous history of PLF. The result is not in line with a study done previously in the district of Mahendragarh in Haryana. ${ }^{9}$

\section{Limitations of the study}

Being a cross-sectional study, there was no possibility to identify whether PLF affects the associated factors and whether there is association or effect between variables. In 
addition, some important variables including social class and spirituality, which were difficult to measure contextually, were not included.

\section{Conclusion and recommendation}

In this study area, the prevalence of PLF is relatively low (19.1\%). The most commonly used prelacteal foods are cow milk, butter, clean water, sugar, honey, salt, and tea. Educational status of the mother, sex of the infant, timing of breast-feeding initiation, site of delivery, and previous experience with PLF were found to be associated with PLF.

Information and educational support should be given for all pregnant mothers regarding the importance of timely initiation of exclusive breast-feeding practice to the newborns. Efforts should also be made to increase rate of institutional delivery.

\section{Acknowledgment}

Our gratitude is extended to Debre Markos University, Debre Markos town administrators, data collectors, and study participants.

\section{Disclosure}

The authors report no conflicts of interest in this work.

\section{References}

1. Holman DJ, Grimes MA. Colostrum feeding behaviour and initiation of breast-feeding in rural Bangladesh. J Biosoc Sci. 2001;33(1): $139-154$.
2. Mukuria AG, Kothari MT, Abderrahim N. Infant and Young Child Feeding Update. Calverton, MA: ORC Macro; 2006.

3. Infant \& Young Child Feeding Quick Reference Book (0-24 months), Ministry of Health Federal Democratic Republic of Ethiopia, 2010.

4. WHO. Global targets 2025: To improve maternal, infant and young child nutrition. 2015; Geneva: WHO.

5. Legesse M, Demena M, Mesfin F, Haile D. Prelacteal feeding practices and associated factors among mothers of children aged less than 24 months in Raya Kobo district, North Eastern Ethiopia: a cross-sectional study. Int Breastfeed J. 2014;9(1):189.

6. Bekele Y, Mengistie B, Mesfine F. Prelacteal feeding practice and associated factors among mothers attending immunization clinic in Harari region public health facilities, Eastern Ethiopia. OJPM. 2014;4(7):529-534.

7. Dawal S, Inamdar I, Saleem T, Priyanka S, Doibale M. Study of pre lacteal feeding practices and its determinants in a rural area of Maharashtra. Sch J App Med Sci. 2014;2(4):1422-1427.

8. Ethiopia Demographic and Health Survey 2011. Addis Ababa, Ethiopia: Central Statistical Agency.

9. Rogers NL, Abdi J, Moore D, et al. Colostrum avoidance, prelacteal feeding and late breast-feeding initiation in rural Northern Ethiopia. Public Health Nutr. 2011;14(11):2029-2036.

10. Raina SK, Mengi V, Singh G. Determinants of prelacteal feeding among infants of RS Pura block of Jammu and Kashmir, India. J Family Med Primary Care. 2012;1(1):27.

11. El-Gilany AH, Abdel-Hady DM. Newborn first feed and prelacteal feeds in Mansoura, Egypt. BioMed Res Int. 2014;2014.

12. Nguyen PH, Keithly SC, Nguyen NT, Nguyen TT, Tran LM, Hajeebhoy N. Prelacteal feeding practices in Vietnam: challenges and associated factors. BMC Public Health. 2013;13(1):932.

13. Verma P, Pandey P, Thakur A. Determinants of pre-lacteal feeding among mothers of newborn: evidence from a Hospital based crosssectional at district Mahendragarh, Haryana. Indian J Appl Res. 2016;6(3).

14. Tariku A, Biks GA, Wassie MM, Gebeyehu A, Getie AA. Factors associated with prelacteal feeding in the rural population of northwest Ethiopia: a community cross-sectional study. Int Breastfeed J. 2016;11(1):14.

15. Ibadin O, Ofili N, Monday P, Nwajei C. Prelacteal feeding practices among lactating mothers in Benin City, Nigeria. Nigerian J Paediatr. 2013;40(2):139-144.
Nutrition and Dietary Supplements

\section{Publish your work in this journal}

Nutrition and Dietary Supplements is an international, peer-reviewed, open access journal focusing on research into nutritional requirements in health and disease, impact on metabolism and the identification and optimal use of dietary strategies and supplements necessary for normal growth and development. The journal welcomes submitted papers covering original research, basic science,

\section{Dovepress}

clinical \& epidemiological studies, reviews and evaluations, guidelines, expert opinion and commentary, case reports and extended reports. The manuscript management system is completely online and includes a very quick and fair peer-review system, which is all easy to use. Visit http://www.dovepress.com/ testimonials.php to read real quotes from published authors. 